\title{
Environmentally Friendly Tannic Acid Multilayer Coating for Reducing Corrosion of Carbon Steel
}

Christy M. Koerner, a David P. Hopkinson, ${ }^{a}$ Margaret E. Ziomek-Moroz, ${ }^{b}$ Alvaro

$$
\text { Rodriguez, }{ }^{c} \text { Fangming Xiang }{ }^{a, \text { * }}
$$

${ }^{a}$ National Energy Technology Laboratory, US Department of Energy, 626 Cochrans Mill Rd, Pittsburgh, PA 15236, USA

${ }^{b}$ National Energy Technology Laboratory, US Department of Energy, 1450 Queen Ave SW, Albany, OR 97321, USA

cPipeline and Hazardous Materials Safety Administration, US Department of Transportation, 3700 S MacArthur Blvd Suite B, Oklahoma City, OK 73179, USA

*corresponding author: fangming.xiang@netl.doe.gov

Keywords: layer-by-layer assembly; corrosion inhibitor; carbon steel; anti-corrosion; tannic acid

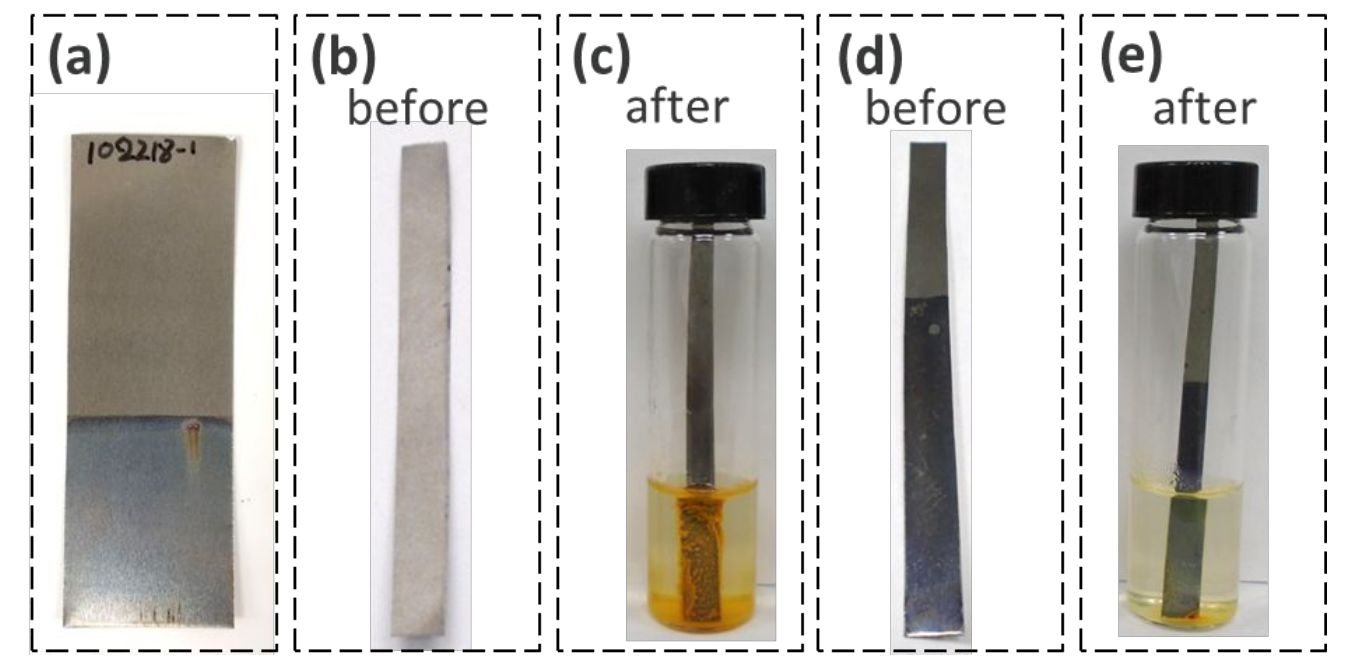

Figure S1. (a) 30 BL TA/PEI deposited via water-assisted LbL assembly, which used water instead of methanol as the solvent for dissolving components, on carbon steel. (b) Carbon steel dipped in $0.1 \mathrm{wt} \%$ methanolic TA solution for $30 \mathrm{~min}$. (c) Sample shown in (b) after being immersed in deionized water 
for 5 days. (d) Carbon steel dipped in $0.1 \mathrm{wt} \%$ aqueous TA solution for $30 \mathrm{~min}$. (e) Sample shown in (d) after being immersed in deionized water for 5 days.

(a)

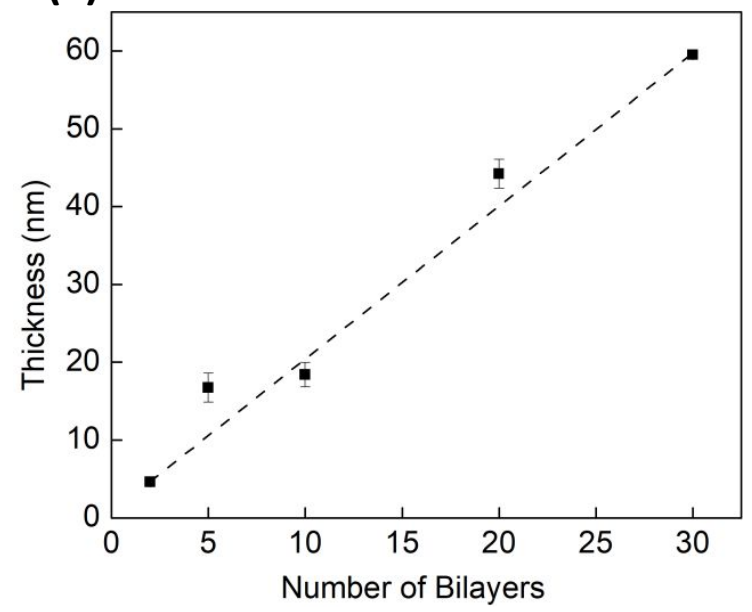

(b)

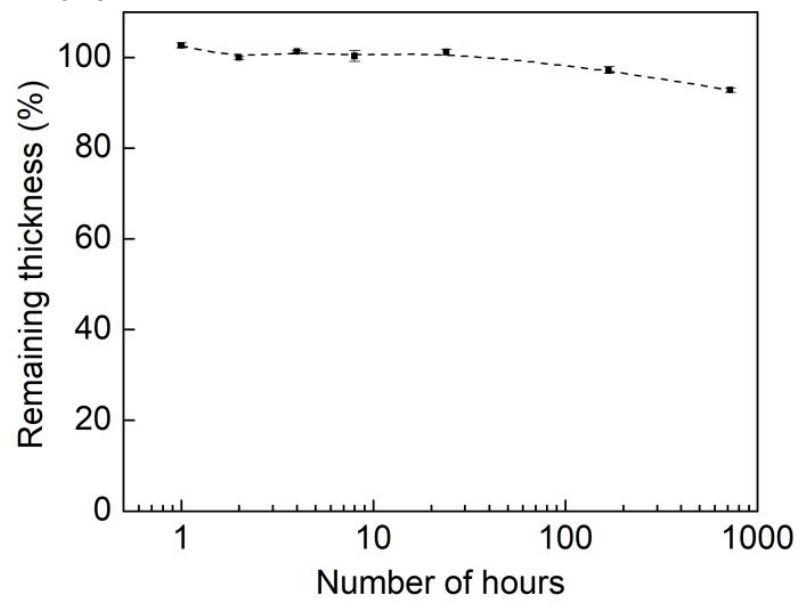

Figure S2. (a) Thickness of TA/PEI bilayers deposited on silicon wafer. (b) Remaining thickness of 30BL TA/PEI bilayers immersed in water as a function of time.

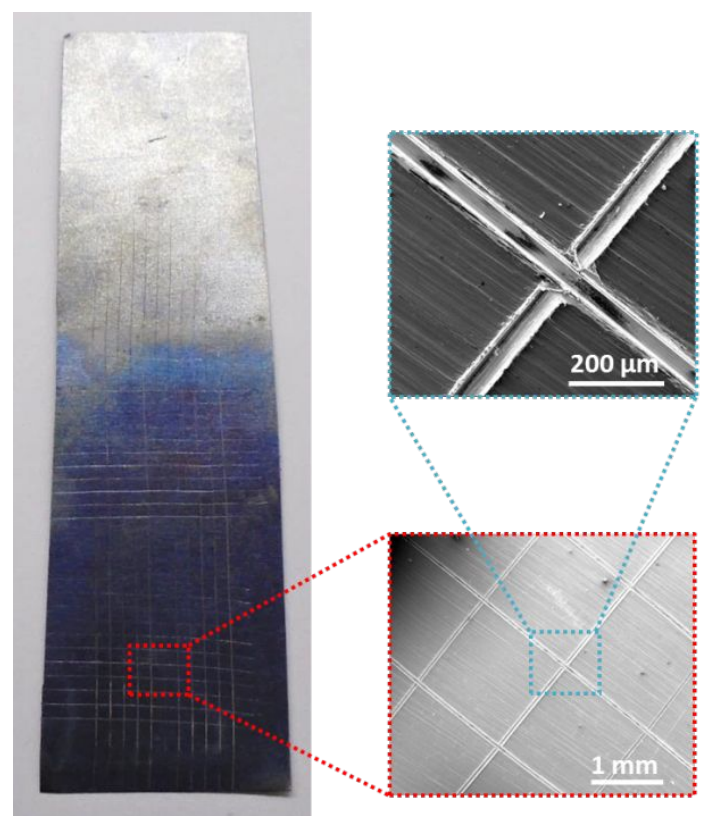

Figure S3. 30BL TA/PEI deposited on carbon steel showed no damage after cross hatch adhesion test performed in accordance with ASTM D3359. 
(a) before immersion

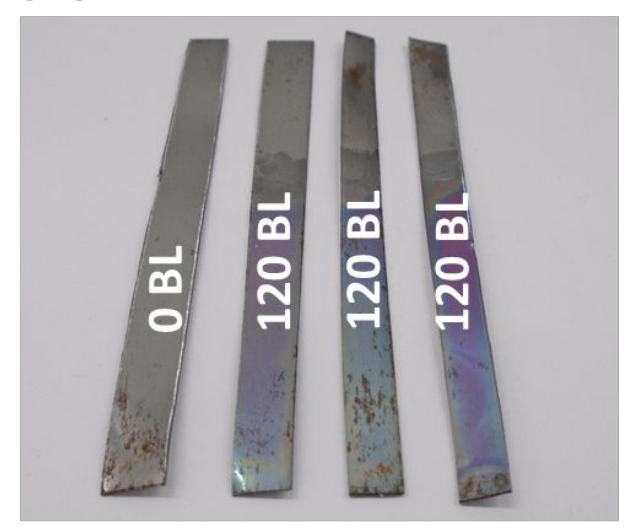

(c)

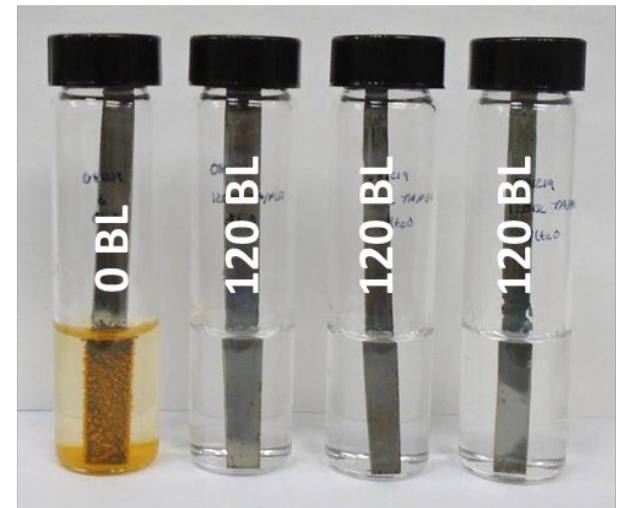

(b) 1-day

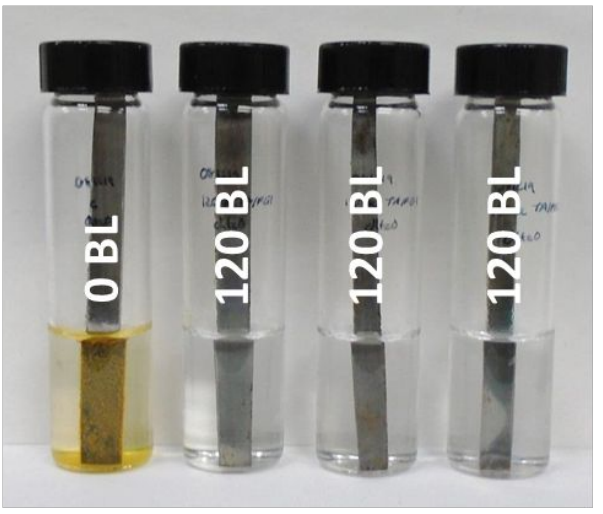

(d) 1-month

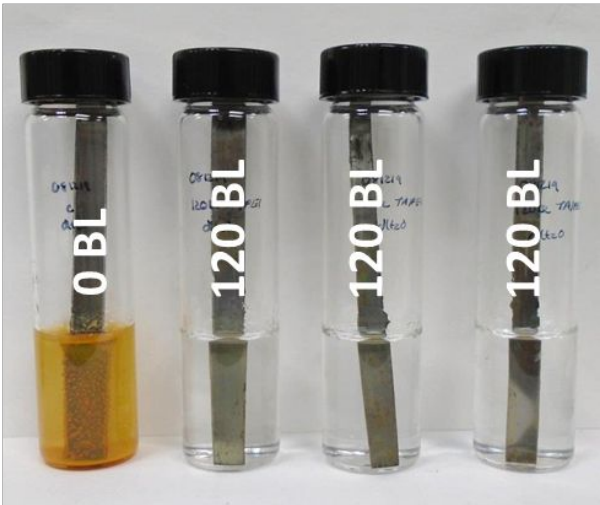

Figure S4. Images of corroded carbon steel with 120BL TA/PEI (a) before and (b-d) after being immersed in deionized water for different durations.

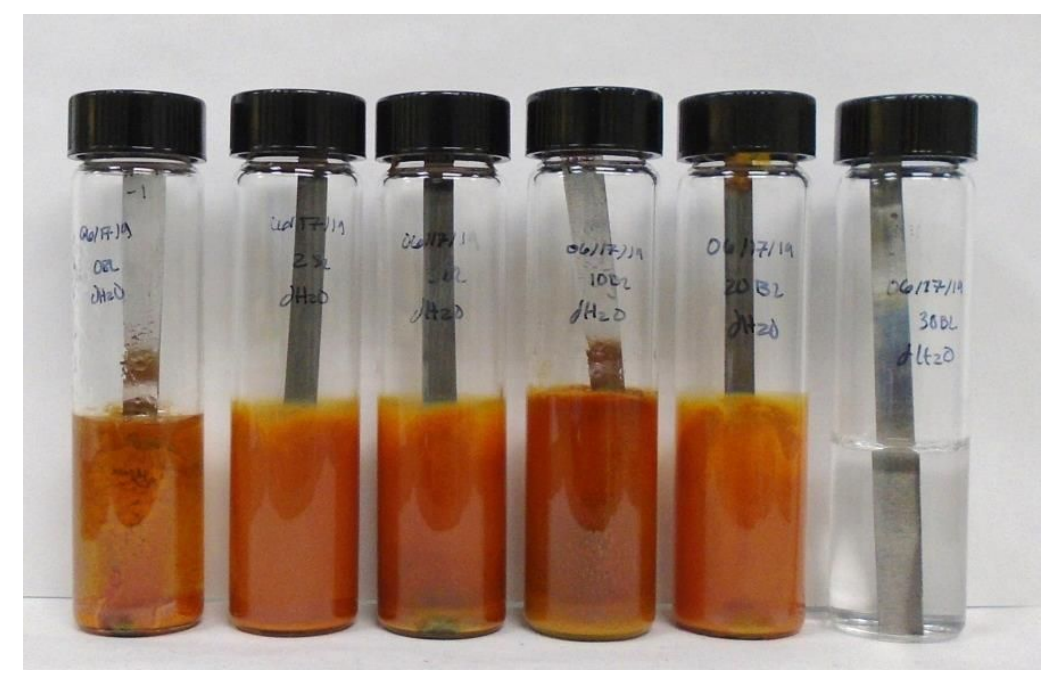


Figure S5. Carbon steel with 0, 2, 5, 10, 20, $30 \mathrm{TA} / \mathrm{PEI}$ bilayers (from left to right) after being immersed in deionized water for 6 months.

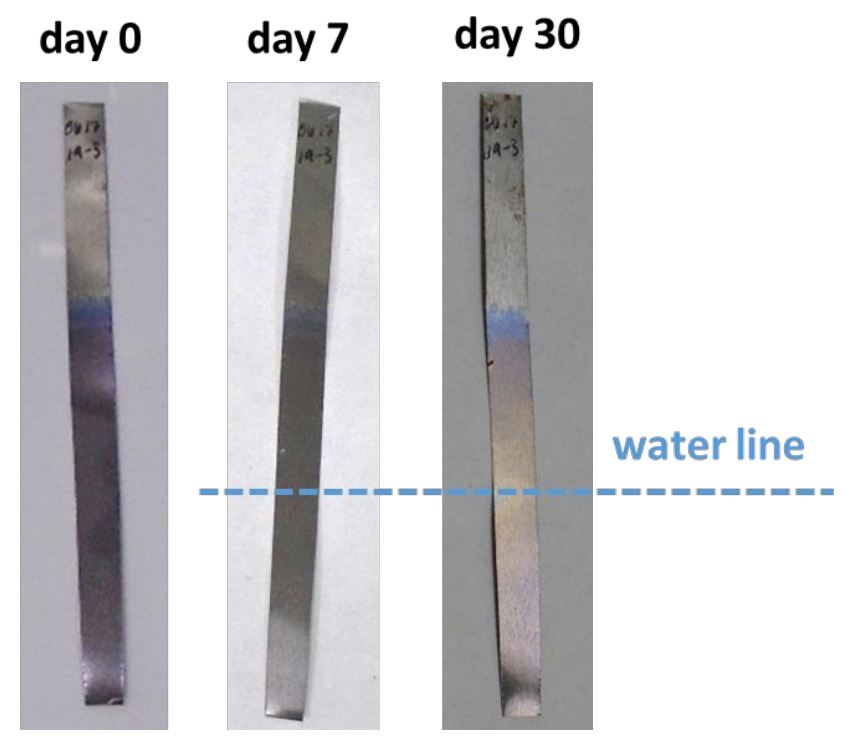

Figure S6. 30BL TA/PEI coated carbon steel as a function of immersion time after being immersed in deionized water with continuous air bubbling.
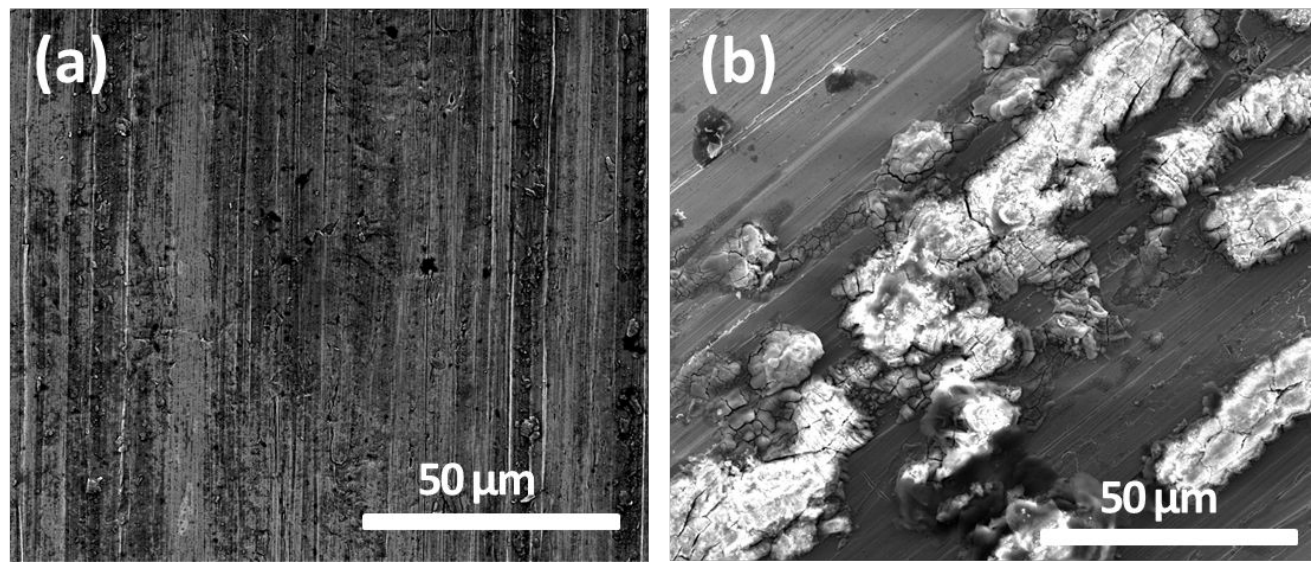

Figure S7. Surface morphology of (a) carbon steel and (b) corroded carbon steel. 


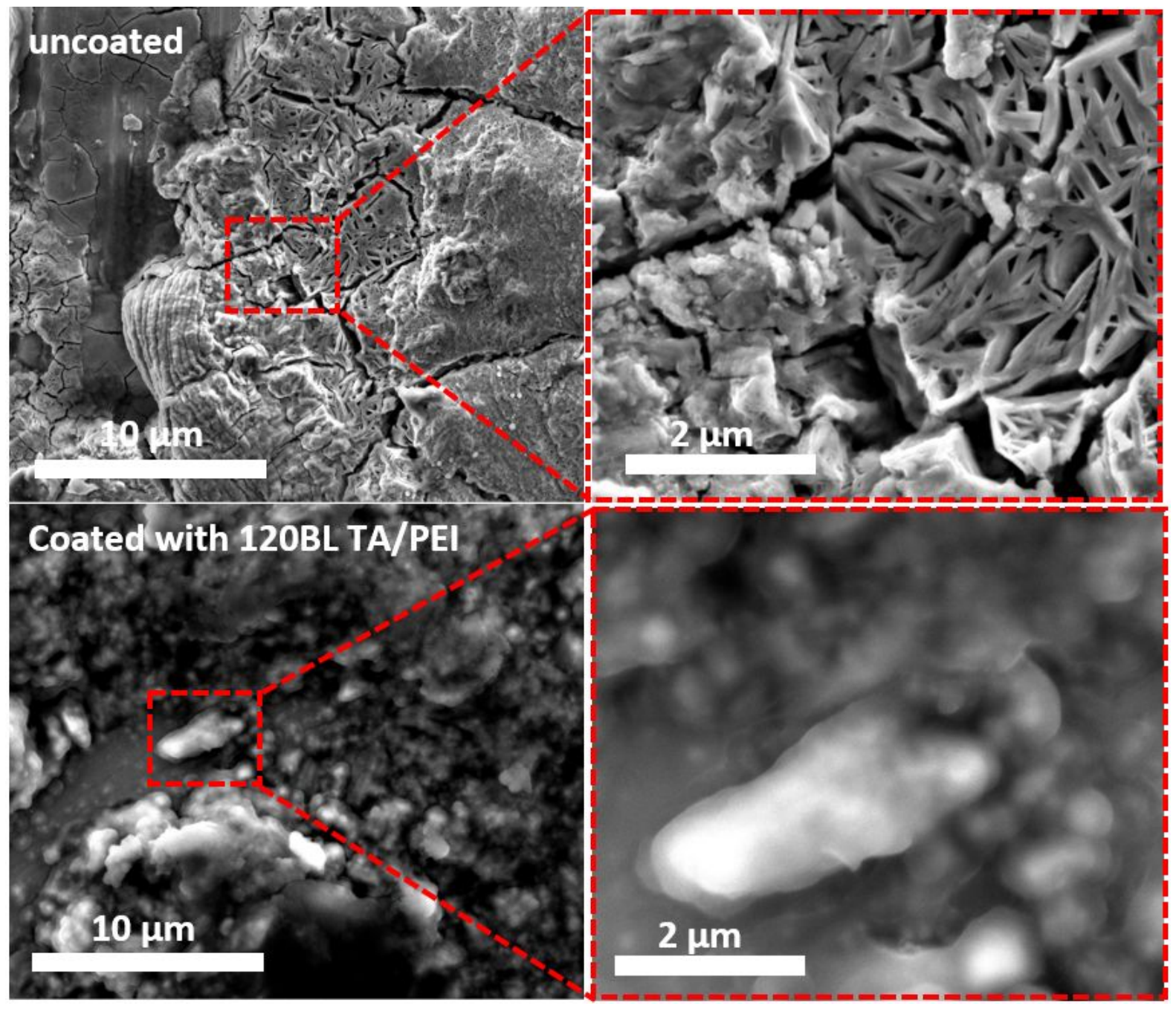

Figure S8. Surface morphology of pre-corroded carbon steel with and without 120BL TA/PEI. 


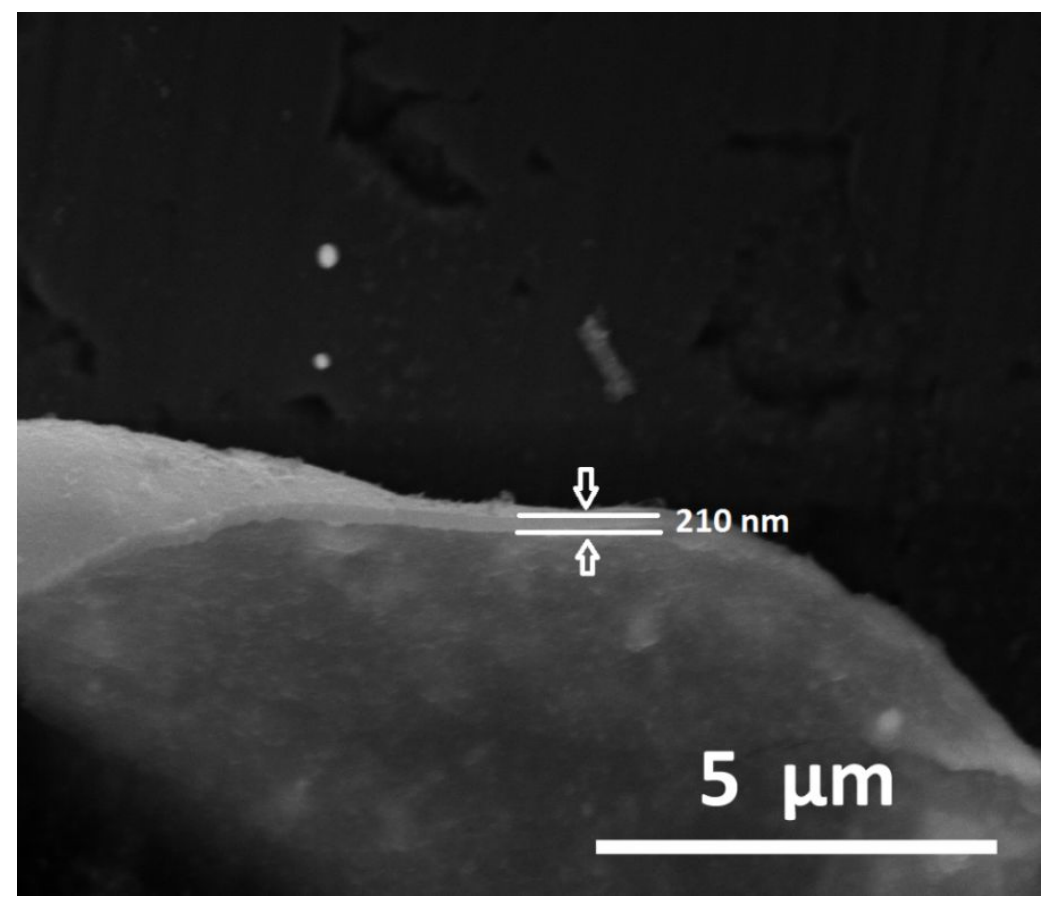

Figure S9. SEM cross-sectional image of a 120BL TA/PEI coating peeled off from the carbon steel surface after being exposed to water saturated $\mathrm{CO}_{2}$ for 3 days.
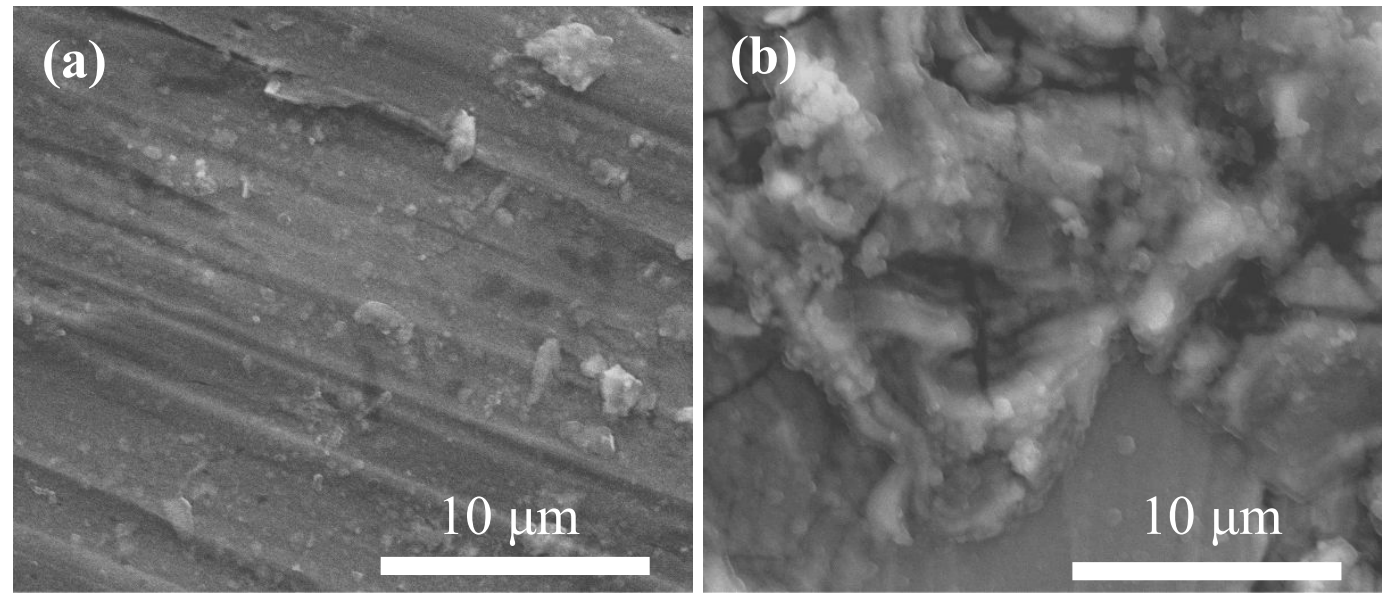

Figure S10. SEM morphology of (a) 30BL TA/PEI on 1008-1010 carbon steel and (b) 120BL TA/PEI on pre-corroded X65 steel after soaking in deionized water for 1 month. 
The oxygen content in 30BL TA/PEI coated 1008-1010 carbon steel was found to be negligible before and after soaking in deionized water for 1 month. The oxygen content in in 120BL TA/PEI coated pre-corroded X65 steel was found to remain at around 25\% after soaking in deionized water for 1 month. These results show no change in elemental composition during corrosion tests, validating the anti-corrosion property of TA/PEI bilayers.

\section{(a)}

Spectrum processing

No peaks omitted

Processing option : All elements analyzed (Normalised)
Number of iterations $=3$

Standard :

C $\mathrm{CaCO} 3$ 1-Jun-1999 12:00 AM

Elem... Weight\% Atomic\%

$\begin{array}{lrr}\text { CK } & 7.44 & 27.21 \\ \text { FeK } & 92.56 & 72.79\end{array}$

Totals $\quad 100.00$
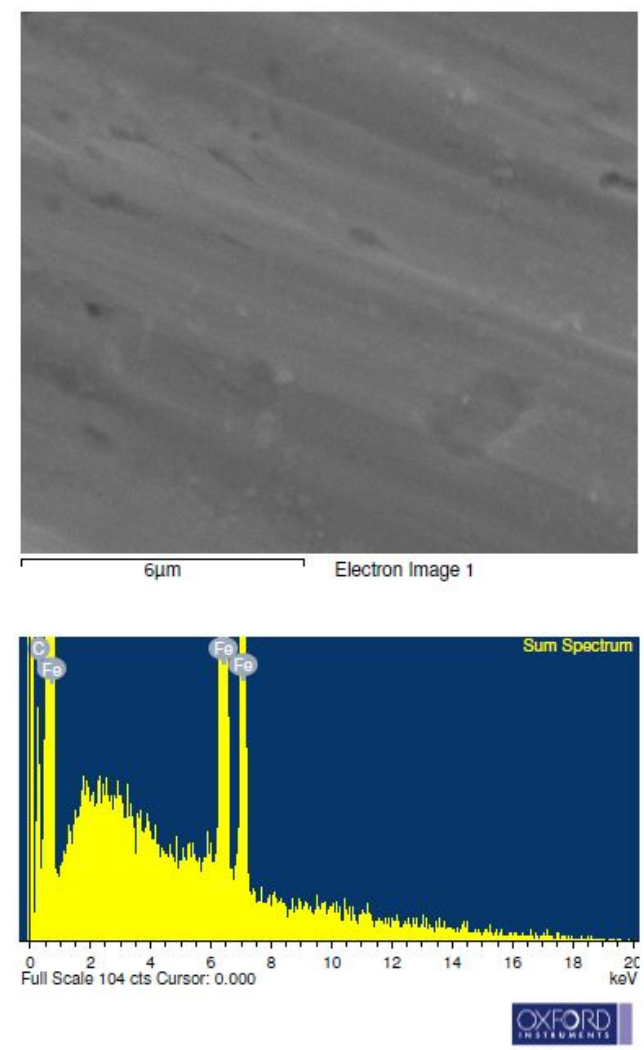
(b)

Spectrum processing :

No peaks omitted

Processing option : All elements analyzed (Normalised)

of iterations $=3$

Standard :

C $\mathrm{CaCO} 3$ 1-Jun-1999 12:00 AM

$\mathrm{Fe}$ Fe 1-Jun 19

Elem... Weight\% Atomic\%

$\begin{array}{lrr}\text { CK } & 6.78 & 25.28 \\ \text { FeK } & 93.22 & 74.72\end{array}$

Totals $\quad 100.00$

(c)

Spectrum processing

No peaks omitted

Processing option : All elements analyzed (Normalised)

Number of iterations $=6$

Standard :

C $\mathrm{CaCO}$ 1-Jun-1999 12:00 AM

S $\mathrm{SiO2}$ 1-Jun-1999 12:00 AM

Si $\quad \mathrm{SiO} 2$ 1-Jun-1999 12:00 AM

$\mathrm{Fe} \mathrm{Fe}$ 1-Jun-1999 12:00 AM

Elem... Weight\% Atomic\%

$\begin{array}{lll}\text { CK } & 47.71 & 65.08\end{array}$

\begin{tabular}{lrr} 
OK & 26.53 & 27.17 \\
Si K & 0.31 & 0.18 \\
\hline PK & 0.41 & 0.22
\end{tabular}

$\begin{array}{lrr}\text { PK } & 0.41 & 0.22 \\ \mathrm{FeK} & 25.04 & 7.35\end{array}$

Totals $\quad 100.00$

Comment:

Comment:
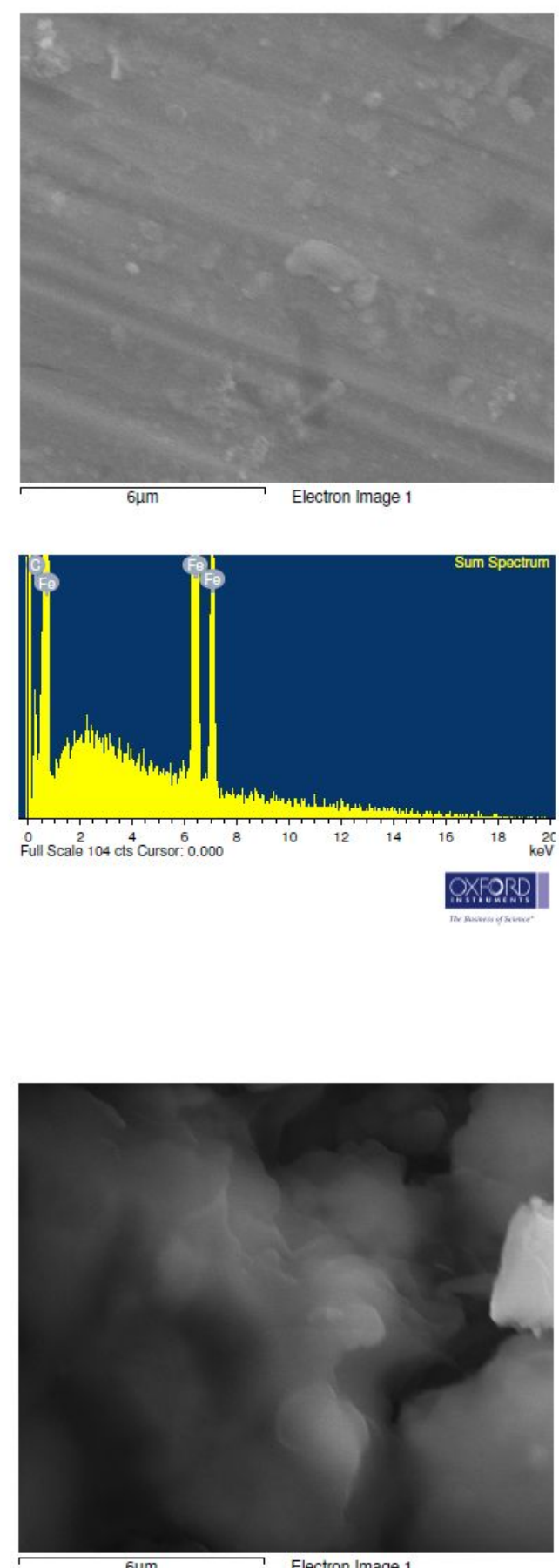

6um Electron Image 1

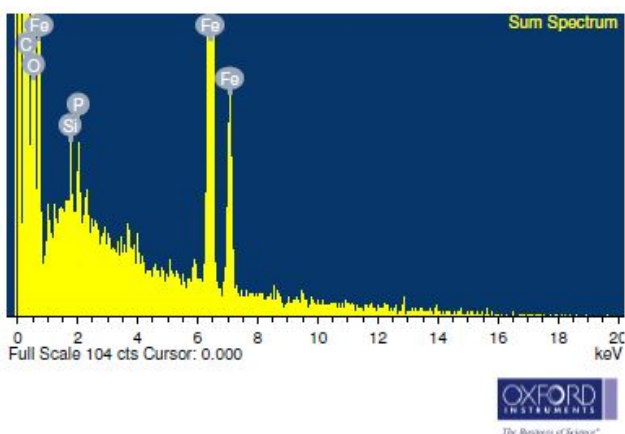




\section{(d)}

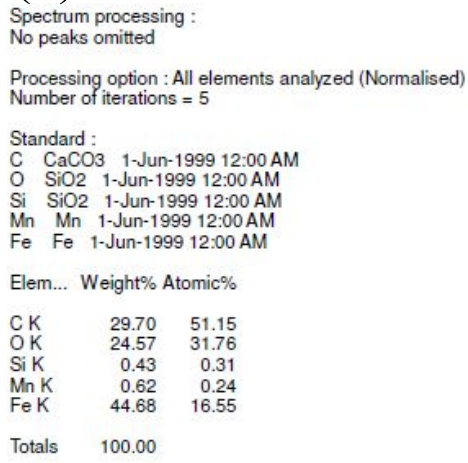

Spectrum processing
No peaks omitted

Processing option : All elements analyzed (Normalised)

Standard

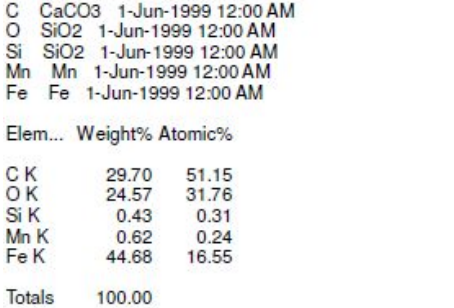

Comment:

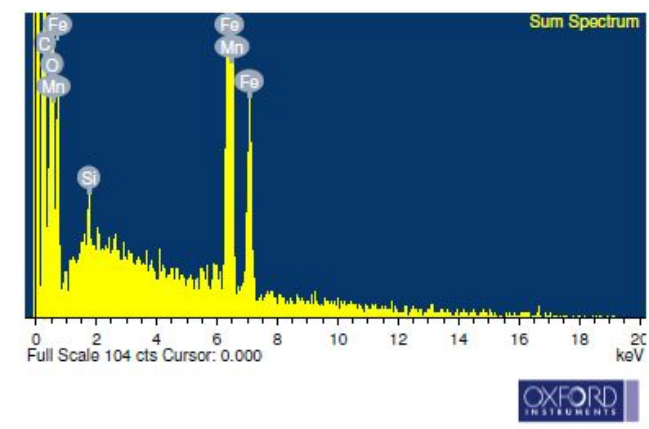

Figure S11. EDX results for 30BL TA/PEI coated 1008-1010 carbon steel (a) before and (b) after soaking in deionized water for 1 month; and for 120BL TA/PEI coated pre-corroded X65 steel (c) before and (d) after soaking in deionized water for 1 month.

The corrosion medium of interest for this study was deionized water, which could not be used as an electrolyte in a polarization test due to its extremely low electrical conductivity (18.2 $\mathrm{M} \Omega)$. Therefore, a low concentration $(0.1 \mathrm{wt} \% \mathrm{NaCl})$ salt solution was used as an approximation of deionized water. When compared with uncoated carbon steel, the addition of 30BL TA/PEI reduced the corrosion current from $1.748 \pm 0.572$ to $0.253 \pm 0.187 \times 10-5 \mathrm{~A}$ and shifted the corrosion potential in the anodic direction from $-0.305 \pm 0.011$ to $-0.274 \pm 0.036 \mathrm{~V}$. These minor changes in corrosion potential and current are disproportionally small when compared with the huge difference in corrosion resistance in deionized water (Fig. 3). 


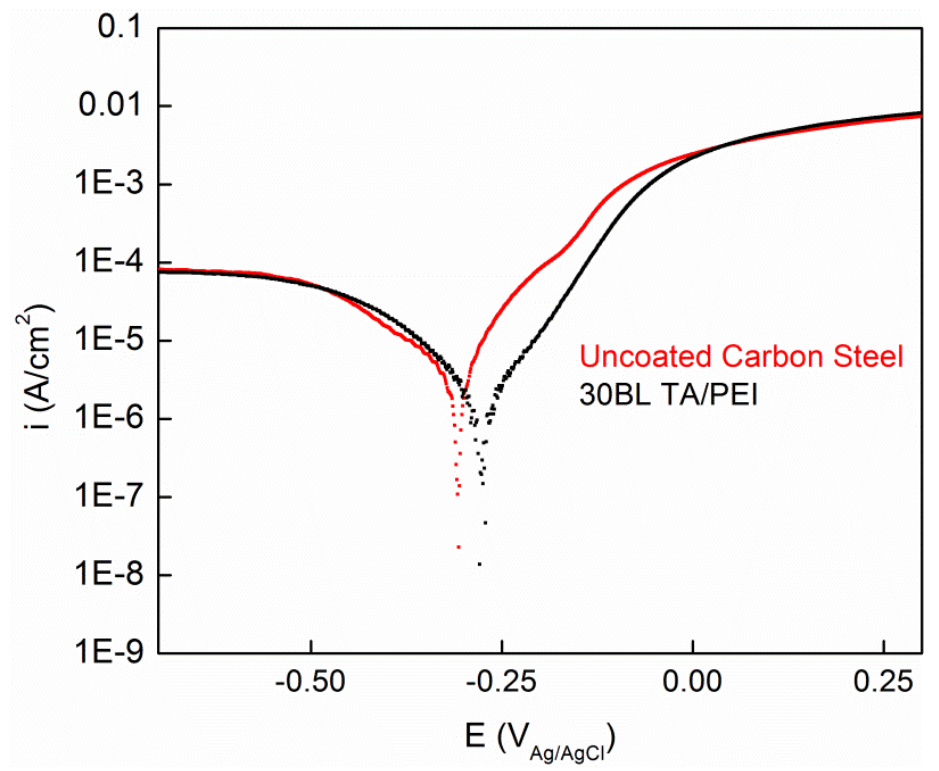

Figure S12. Typical polarization curves of carbon steel with and without 30BL TA/PEI in 0.1 $\mathrm{wt} \% \mathrm{NaCl}$.
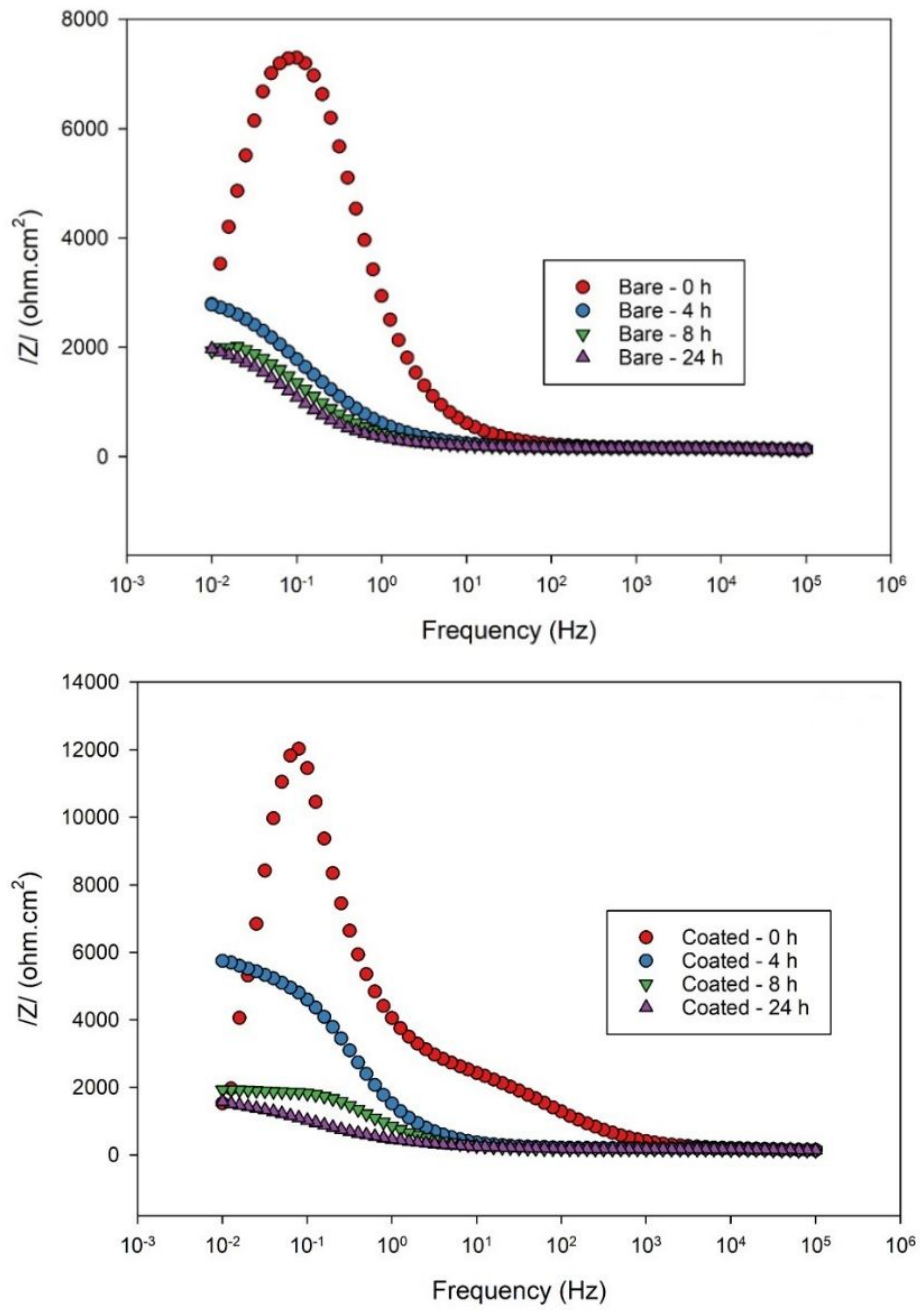

Figure S13. Typical electrochemical impedance spectroscopy of carbon steel with and without 30BL TA/PEI in $0.1 \mathrm{wt} \% \mathrm{NaCl}$ as a function of time. 


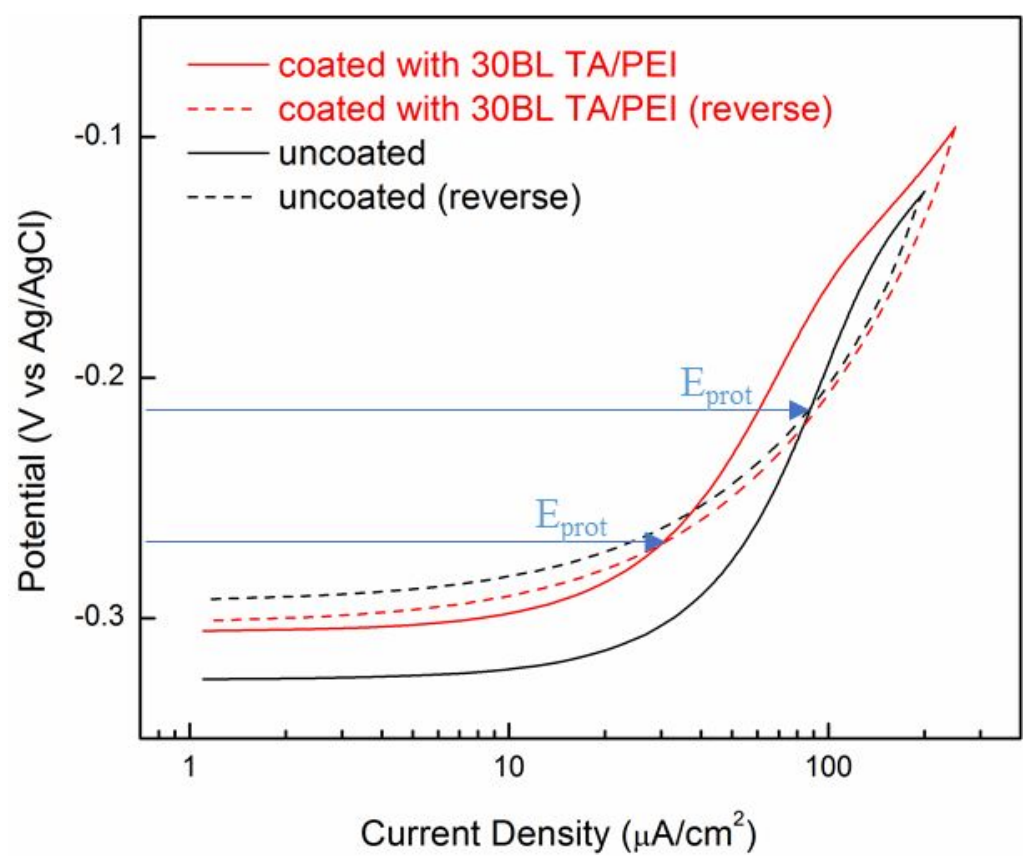

Figure S14. Cyclic voltammograms of carbon steel with and without 30BL TA/PEI in $0.1 \mathrm{wt} \%$ $\mathrm{NaCl}$. The crossover of forward and reverse scans is known as protection potential $\left(\mathrm{E}_{\text {prot }}\right)$, with lower protection potential corresponding to higher tendency of localized corrosion. ${ }^{1}$

$\mathrm{NaCl}$ or $\mathrm{CO}_{2}$ can generate large amounts of charged ions in water, which would disrupt the original ionic bonds between $\mathrm{TA}^{-}$and $\mathrm{PEI}^{+}$by competing to combine with them. ${ }^{2}$ This competition likely caused TA/PEI bilayers to swell in water, ${ }^{3}$ which either allows ions to permeable through this protective coating or decomposes expose part of the surface that was previously covered by this passivating film and eventually led to corrosion.

(a)

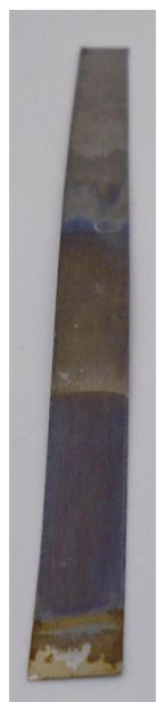

(b)

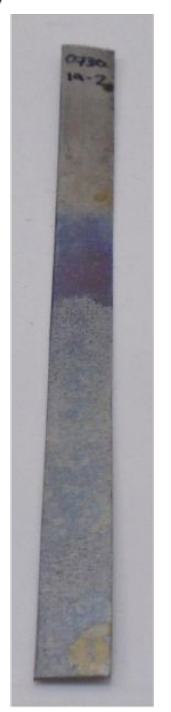

Figure S15. 30 bilayers TA/PEI coated carbon steel submerged in (a) $3.5 \mathrm{wt} \% \mathrm{NaCl}$ solution for 24 hours, (b) $\mathrm{CO}_{2}$ saturated deionized water for 4 hours. 


\begin{tabular}{|c|c|c|c|c|c|}
\hline & $\begin{array}{c}\mathrm{E}_{\text {corr }} \\
(\mathrm{V})\end{array}$ & $\begin{array}{c}\mathrm{I}_{\text {corr }} \\
(\mathrm{A})\end{array}$ & $\begin{array}{c}\text { Tafel slope } \\
\text { [anode] } \\
(\mathrm{V} / \mathrm{dec})\end{array}$ & $\begin{array}{c}\text { Tafel slope } \\
\text { [cathode] } \\
(\mathrm{V} / \mathrm{dec})\end{array}$ & $\begin{array}{c}\text { Corrosion rate } \\
(\mathrm{mm} / \text { year })\end{array}$ \\
\hline uncoated & -0.313 & $4.17 \times 10^{-06}$ & 0.0323 & 0.0769 & 0.0484 \\
\hline coated & -0.280 & $1.14 \times 10^{-06}$ & 0.0393 & 0.0395 & 0.0132 \\
\hline
\end{tabular}

Table S1. $\mathrm{E}_{\text {corr }}, \mathrm{I}_{\text {corr }}$, Tafel slopes, and corrosion rates derived from linear polarization experiment using $0.1 \mathrm{wt} . \% \mathrm{NaCl}$ aqueous solution as the electrolyte.

\section{References}

1. Jones, D. A., Principles and prevention of corrosion. Macmillan: 1992.

2. Dubas, S. T.; Schlenoff, J. B., Polyelectrolyte multilayers containing a weak polyacid:

Construction and deconstruction. Macromolecules 2001, 34 (11), 3736-3740.

3. Dubas, S. T.; Schlenoff, J. B., Swelling and smoothing of polyelectrolyte multilayers by salt. Langmuir 2001, 17 (25), 7725-7727. 